\title{
La larga transición en Indonesia
}

$\mathrm{L}$ a transición política en Indonesia se prolonga. Con su asunción a la presidencia en julio pasado, Megawati Sukarnoputri, de 54 años de edad, es la cuarta ocupante de la residencia oficial en tres años. La incógnita que permanece, sin embargo, es si será capaz de completar los 27 meses que restan al periodo presidencial de su antecesor.

La primera mandataria simboliza el misterio respecto al futuro político de este archipiélago de 210 millones de habitantes, el cuarto país más poblado del planeta. Hija de Achmed Sukarno, el primer presidente de Indonesia y que fuera depuesto en un golpe de estado por Mohamed Suharto en 1965-1966, Megawati entró a la escena política hace relativamente poco, a mediados de los noventa. En este corto periodo parece que se ha esforzado por hacer que sus ideas políticas sean una incógnita para propios y extraños. Poco afecta a pronunciar discursos o a conceder entrevistas, Megawati ha cultivado una imagen de retraimiento. Así, por ejemplo, el fin de semana previo a su toma de posesión, con la crisis política en plena efervescencia, prefirió irse al cine a ver la película infantil Shrek en lugar de tomar parte en las intensas negociaciones políticas que se llevaban a cabo.

Pero ese aparente alejamiento no quiere decir que la flamante presidenta sea ajena al

* Investigador del Departamento de Estudios del Pacífico de la Universidad de Guadalajara. lenguaje del poder - como su ascendencia misma lo sugiere. Sabedora de lo que el legado de su padre significa tanto para el imaginario popular como para las fuerzas armadas, su primer acto como jefa de estado fue visitar los restos de su padre. Por lo demás, una de las pocas cuestiones en que Megawati ha hecho clara su postura tiene que ver precisamente con su coincidencia con los puntos de vista de los altos mandos militares. Siendo más proclive a la mano dura que su antecesor, el defenestrado Abdurrahman Wahid, es probable que Megawati otorgue más rienda suelta a los militares en su trato con los movimientos separatistas (en Aceh, en la punta norte de Sumatra, y en Irian Jaya, en la isla que Indonesia comparte con Papua Nueva Guinea).

necesaria para llevar
a buen puerto una
eventual transición a
un régimen
democrático

La consolidación institucional en Indonesia es necesaria para llevar tendrá un papel importante en dotar a este todavía volátil periodo de cierta estabilidad. En el último trienio el ejército ha perdido su papel de "protector" del sistema político y de la burocracia gubernamental. Todavía más, desde la administración anterior, el ministro de defensa es un civil. El mandato de Wahid, que duró sólo 21 meses, no sólo no logró consolidar las instituciones, sino que tuvo a dos de ellas, en particular el parlamento y el ejército, como una amenaza para la consolidación de la institución presidencial. No es sorprendente, pues, que Wahid nunca haya logrado asumir realmente las funciones presidenciales. Como Daniel Lev, especialista en Indonesia de la 
Universidad de Washington, lo planteó recientemente, no existe en la actualidad una sola institución estatal funcionando adecuadamente en Indonesia: "Uno puede decir genuinamente que Indonesia no tiene un estado en estos momentos" (New York Times, julio 25, 2001).

Así pues, la estabilidad que las fuerzas armadas parecen estar dispuestas a ofrecer se antoja vital para la supervivencia del régimen de Megawati. De hecho, el mismo Wahid otorgó en bandeja de plata a la institución castrense una oportunidad que ésta supo aprovechar para limpiar su imagen. Ante la amenaza parlamentaria de iniciar un juicio político en su contra, el convaleciente ex mandatario respondió con la amenaza de imponer el estado de emergencia, pero cuando intentó llevar a cabo esta medida, los altos mandos militares simplemente no le obedecieron. Así, el ejército quedó, aunque fuera momentáneamente, como el ente heroico de la, afortunadamente, pacífica transmisión de poder. Detrás de este acto de heroísmo estaba, por supuesto, la abierta confrontación del ejército con Wahid. De cualquier manera, el abierto abandono del mandatario, que por unanimidad parlamentaria era depuesto en esos días, permitió a las fuerzas armadas cimentar su alianza con Megawati.

Sin embargo, hablar de un proyecto de consolidación institucional en Indonesia en estos momentos no es lo mismo que hablar de la consolidación que el país necesita para llevar a buen puerto una eventual transición a un régimen democrático. A pesar de que el ejército ha hecho avances serios en su reforma, goza todavía de un peso relativo desproporcionado para un estado plenamente democrático. Así, en agosto del 2000, la asamblea aprobó una incitativa por medio de la cual se extiende la representación militar en el parlamento hasta el año 2009, en lugar de expirar en 2004, como se había establecido en la legislación anterior. La burocracia estatal, por otro lado, ha cambiado muy poco, si es que ha cambiado algo, desde la caída de Suharto, y la elite empresarial que apoyaba a éste permanece intacta.

Afortunadamente para Megawati, y en contraste con su sucesor, ella cuenta no sólo con el apoyo del ejército, sino también con el de un segundo elemento potencialmente estabilizador: el parlamento. Mientras que el partido de Wahid, Despertar Nacional, controlaba el 10 por ciento de la cámara baja cuando era presidente, el de Megawati, el Partido Democrático Indonesia por la Lucha, controla el 35 por ciento. Más todavía, Megawati (o sus operadores políticos), estableció una especie de matrimonio por conveniencia con el Partido del Desarrollo Unido (musulmán) que al parecer asegura su supervivencia por los próximos tres años. La jugada consistió en aceptar que el líder del partido islámico, Hamza Haz (el mismo que en octubre de 1999 se opusiera a que Megawati ocupara la presidencia "argumentando" que su condición de mujer le impedía ocupar la primera magistratura), sea su vicepresidente. Así, dado que el prospecto de ver al actual vicepresidente convertirse en presidente (esto es, repetir la historia de Megawati) no parece atractivo para la mayoría de los parlamentarios, las probabilidades de que Megawati concluya su periodo se incrementan significativamente. Este matrimonio por conveniencia de las fuerzas islámicas representadas por el vicepresidente y el nacionalismo democrático representado por Megawati parece, pues, aumentar las posibilidades de estabilidad en Indonesia—por lo menos hasta 2004, en que se celebrarán elecciones presidenciales.

Un tercer elemento que parece incrementar los prospectos de estabilidad en la era de Megawati es su gabinete. Irónicamente, exactamente un año después de que Wahid pronunciara un discurso en el que prometió reestructurar su gabinete y retirarse del manejo cotidiano de la administración, y de que declarara que "lo que se le ha entregado a la vicepresidenta [Megawati] no es autoridad sino tareas" (Far Eastern Economic Review, agosto 
24, 2000), Megawati anunció su gabinete-ya como presidenta con plena autoridad y no sólo con "tareas" que desempeñar. Los buenos augurios para la administración de Megawati tienen que ver con la buena acogida que recibió la composición de su equipo de trabajo. El gabinete económico está compuesto por un equipo de tecnócratas ortodoxos, por lo que fue bien recibido por los inversionistas y las instituciones financieras. El ministro de Coordinación Económica, Dorodjatun KuntoroJakti, es un economista que fue embajador en Estados Unidos. El ministro de finanzas, Budonio, fue titular de la oficina de planeación económica nacional. Su principal tarea será incrementar, o al menos mantener, el crecimiento de la economía indonesia, el cual fue de 4.8 por ciento el año pasado (en contraste con un crecimiento de 0.8 por ciento en $1999 \mathrm{y}$ una contracción de 13.1 por ciento en 1998).

En lo que respecta a cuestiones de política y seguridad, Megawati dejó en claro que su prioridad es la consolidación y la estabilidadalgo que también fue bien visto por los mercados. Como encargado de seguridad nacional designó a un exgeneral con fama de reformista, Bambang Susilo Yudhoyono, quien ocupó la misma cartera con Wahid hasta que éste lo destituyó. Como canciller, Megawati eligió a un diplomático de carrera, Hassan Wirayudha, lo que manda un claro mensaje de profesionalizar esta cartera también. En el ministerio de defensa, como adelanté más arriba, Megawati continuó la práctica establecida por su antecesor de poner al frente a un civil, en este caso a Matori Abdul Djalil. Su elección como procurador general, una posición de máxima importancia dado el abultado número de casos de corrupción de la era Suharto que permanecen sin concluir, en cambio, ha decepcionado. El cargo recayó en M. A. Rachman, un funcionario de segundo nivel que se había ocupado de la investigación de violaciones a los derechos humanos cometidas en Timor Oriental tras el voto independentista de 1999, y en la cual fueron exonerados algunos generales del ejército que se encontraban entre los principales sospechosos.

Sin embargo, más allá de la estabilidad que el ejército, el parlamento y su gabinete puedan proporcionar al régimen de Megawati, poniendo así fin al periodo de transición iniciado con la caída de Suharto, será determinante para el legado que Megawati deje a su país el tipo de liderazgo que ella imprima a su mandato. Es claro a estas alturas que, dado el momento que vive su país, así como su propia personalidad, Megawati será una figura de transición, tal como lo fue Corazón Aquino en Filipinas o Violeta Barrios en Nicaragua. Ella misma declaró recientemente que no le molesta ser considerara como una ama de casa (Los Angeles Times, julio 29, 2001). Ciertamente no es ese un perfil tradicionalmente asociado con un estadista, aunque más le valdría asemejarse a una de estas dos ex presidentas, y no a la ex primer ministro pakistaní Benazir Bhutto, quien, como Megawati, tuvo tanto un padre prominente como un esposo incómodo (el esposo de Megawati es un exitoso empresario con conexiones por demás dudosas).

En todo caso, Megawati parece sentirse más atraída por la actual presidenta de Filipinas, Gloria Macapagal Arroyo, quien, como Megawati, también era vicepresidenta antes de asumir la primera magistratura, y también es hija de ex presidente. Es precisamente Gloria Macapagal Arroyo a quien Megawati visita en su primer periplo al exterior. Desafortunadamente todo parece indicar que algo que no tendrá en común con su homóloga filipina es claridad de ideas propias (ver al respecto el número 11 deMéxico y la Cuenca del Pacífico). Así pues, parece que la transición política en Indonesia se prolongará al menos otros tres años, si es que un nuevo presidente con visión y legitimidad propias es electo en 2004. 